\title{
Filosofía experimental en Nietzsche y una posible explicación sobre el porqué del estilo aforístico de La gaya scienza (1882) *
}

Experimental philosophy in Nietzsche and a possible explanation about the reason behind aphoristic style of La gaya scienza (1882)

Por: Ríos, Joaquín Gabriel* Universidad Nacional del Nordeste

E-mail: Joaquinfaq19@gmail.com

Fecha de recepción: 14/03/2020

Fecha de aprobación:20/04/2020

DOI: $10.30972 /$ ach.054319

\section{Resumen}

La razón por la cual Nietzsche elige el estilo aforístico es un enigma que no posee una respuesta unívoca, por lo que en este trabajo lo que se plantea es una posible respuesta a éste enigma. Siempre y cuando tomemos en cuenta la postura de Andreas Urs Sommer y el trabajo presentado por Osman Daniel Choque (2018). También será de suma importancia plasmar una pequeña mirada acerca de la obra Ecce homo: cómo se llega a ser lo que se es (1908), y relacionarlo, a su vez, con aforismos de La gaya ciencia (1882). De esta manera podremos aportar una explicación a dicho problema.

Palabras claves: Nietzsche, aforismos, enigma, postura, explicación.

\footnotetext{
Abstract

The reason why Nietzsche choose the aphoristic style is an enigma that does not have a univocal answer, so in this work what is posed is a possible response to this

* El presente trabajo surgen en marco de la cátedra Seminario I. Análisis de una obra filosófica del año 2019.

*Estudiantx de la Licenciatura en Filosofía de la Facultad de Humanidades (UNNE).
} 
enigma. As long as we take into account the position of Andreas Urs Sommer and the work presented by Osman Daniel Choque (2018). It will also be of utmost importance to capture a small look about the work Ecce homo: how it becomes what it is (1908), and relate it, in turn, with aphorisms of La gaya science (1882). In this way we can provide an explanation for this problem.

Keywords: Nietzsche, aphorisms, enigma, position, explanation.

\section{Cómo citar este artículo:}

APA: Ríos, J. G. (2020). Filosofía experimental en Nietzsche y una posible explicación sobre el porqué del estilo aforístico de La gaya scienza (1882), Acheronta, 5, 96-113. Recuperado de: (agregar dirección web)

\section{Introducción}

La presente monografía intenta dar una posible explicación al problema de por qué, Nietzsche, utiliza el estilo aforístico en su obra La gaya ciencia (1882). Éste estilo pretende una función sumamente filosófica, o intenta una distinción de la pesada filosofía tradicional que se venía arrastrando, o si, por el contrario, es una síntesis de ambas suposiciones. Como es preciso destacar, éste trabajo sólo se centrará en la obra de Nietzsche, La gaya ciencia (1882) y la intención escondida detrás del estilo aforístico que utiliza. Adaptando nuestra mirada con relación a la de Andreas Urs Sommer, es decir, tomaremos como principio que esta obra es producto de una filosofía experimental ${ }^{1}$ propia en Nietzsche, obra en donde el autor esconde herramientas lingüísticas para que el propio lector genere su perspectiva a determinados hechos, por ejemplo: imaginarnos un mundo sin Dios, un mundo donde prestemos más atención a lo vital e instintivo, donde lo malo no sea tomado como perjudicial para cada individuo, entre otros. Más precisamente ¿Por qué elige el estilo aforístico Nietzsche?

\footnotetext{
${ }^{1}$ Éste término es explicado por Osman Choque, D $(2018$, p. 5)
} 
Abril 2020.

\section{Desarrollo}

El tema de la gran amplitud lingüística en las obras de Nietzsche es una cuestión que viene siendo tratada. Sobre todo, el estilo aforístico de Nietzsche que marcó una gran influencia después de su llegada. El aforismo es un estilo que fue utilizado por múltiples pensadores, incluso antes de Nietzsche, como Heráclito de Éfeso. Tal y como lo expresa en su trabajo Constantino Láscaris, Heráclito Sobre la naturaleza ${ }^{2}$, podemos encontrar fragmentos aforísticos que tratan sobre la naturaleza en general, sobre el humano, los animales, etc. Podemos ver también ejemplos como Blaise Pascal, donde en su obra más celebre Pensamientos (2012), expone una serie de fragmentos apologéticos de la doctrina cristiana. Incluso podemos situarnos años después de las obras de Nietzsche y encontrar influencias del estilo aforístico. En Emil Cioran, hablamos de la obra Ese maldito yo (1982), que está elaborada con el mismo estilo del que venimos hablando; reflexiones filosóficas en formato de aforismos referentes a temas como la muerte, edad, la religión, entre otros.

Actualmente hay muchas dudas acerca del amplio repertorio de formatos lingüísticos que utiliza Nietzsche en sus obras. Por ejemplo, Nehamas en su obra La vida como literatura (2002), se plantea este problema; Por qué Nietzsche varía tanto de estilos en las escrituras de sus obras. Propone un repaso extenso sobre las obras del autor, además de que las clasifica por etapas, Nehamas puede ver cómo Nietzsche varía de estilos en los tres períodos de su vida, la primera es la etapa juvenil, luego la mediana y, por último, la etapa antes de la locura. La inquietud de la obra de Nehamas es precisamente la variación estilística ¿Tendrá algún significado? Para él, Nietzsche utiliza una variación porque tiene un papel filosófico dentro de cada obra, que, además, es crucial para la escritura y elaboración de la misma. Siguiendo las palabras de Nehamas, hace un repaso de distintos intérpretes que se ocuparon, de manera directo o indirectamente, de esta problemática. Llega a nombrar a Sarah Kofman, ella propone una mirada un poco peculiar, donde la metáfora y el aforismo tienen una función profética, es decir, ambas están plenamente dirigidas a los "espíritus libres";

\footnotetext{
${ }^{2}$ Trabajo recuperado de internet.
} 
aquellos a los que tanto se refería Nietzsche, y ellos serían capaces de captar el significado de los mismos.

A su vez, Nehamas, también llega a nombrar a Martín Heidegger, donde los escritos póstumos de Nietzsche cobran un papel fundamental para la interpretación del mismo. La lectura de los fragmentos de las obras nietzscheanas, deben ser reconstruidas para así llegar a elaborar su verdadero pensamiento, con el cual es la sentencia y culminación de la filosofía occidental.

Por otro lado, Nehamas se toma la molestia de también analizar a Walter Kauffman, considerado uno de los más famosos intérpretes de Nietzsche, donde llega a decir que el tan aclamado estilo aforístico y su fragmentación en las obras de Nietzsche toma un papel crucial porque es una suerte de filosofía problemática. Esto quiere decir, que lo separa de la tradición filosófica, lo hace diferenciarse de la filosofía sistemáticamente estructurada; Nietzsche representa más bien un pensador problemático, sus aforismos no generan soluciones, más bien problemas, interrogantes. Cada fragmento estaría siendo un experimento, que está situado dentro de una unidad integral, cada parte de los fragmentos es un engranaje fundamental de un todo y, por ende, no estarían aisladas y sin conexión alguna.

El mismo Gilles Deleuze en su obra Nietzsche (1965), lo presenta como un pensador que cambió completamente la filosofía tradicional con su estilo de aforismos y su función poética, por un lado, el primero representa una forma de abrir las mentes a la hora de leerlos, resulta un ejercicio de interpretación del mismo. Por el otro, la segunda función, es la encargada de la evaluación, tanto de los valores morales, individuales, etc.

Para ser más certeros, no se sabe a ciencia exacta cuál es el motivo del estilo de aforismos, tampoco ni por qué decidió, Nietzsche, utilizar el mismo. ¿Se puede decir que el estilo aforístico en La gaya ciencia (1882) cumple un papel filosófico? O por el contrario ¿Es un mero capricho de Nietzsche por diferenciarse de la sistematización tradicional y optar por otro estilo menos propio de ella? ¿Podemos tomar esta obra como producto literal de su pensamiento genuino o es simplemente una exhortación a 
Abril 2020.

ISSN 2344-9934

pensar por nosotros mismos? Es decir, es el reflejo de su pensamiento o más bien Nietzsche nos invita a elaborar nuestros propios pensamientos y valores con cada aforismo. Para esclarecer un poco mejor estas cuestiones, es preciso mencionar el trabajo realizado por Oscar Daniel Choque titulado: El filósofo y su filosofía: La "filosofía experimental" de Nietzsche (2018). Muy interesante para traer a colación el tema de la filosofía experimental desarrollada por Andreas Urs Sommer y relacionarla con el estilo aforístico, ya que para esta postura los escritos de Nietzsche no son meros pensamientos suyos, sino más bien, la intención es proporcionarnos una herramienta lingüística para nosotros elaborar nuestras perspectivas y pensamientos frente a determinadas situaciones, como puede ser un mundo lejos de los mandamientos divinos.

Haciendo una síntesis de lo que Kauffman y Sommer plantean, es preciso destacar que es muy probable que la filosofía de Nietzsche tenga un valor experimental, es decir, proporciona al lector una serie de herramientas que sirven a la propia experimentación del mismo. Oscar Daniel Choque (2018) hace muy evidente este tipo de fundamento cuando explica que lo que trata de aportarnos el aforismo 125 es una herramienta que, más que aclararnos, nos induce a una experimentación; el lector va a profundizar y tomar ese "Dios, ha muerto" para luego imaginarse una vida producto de ese acontecimiento; ya que la figura del loco no es la representación del pensamiento de Nietzsche, más bien, trae hacia el lector un escenario (aquel en donde ya no está presente el castigo y la verdad de Dios) para que se imagine y experimente dicho escenario. Dicho de manera resumida, Nietzsche a través de sus escritos, hace uso de estos diferentes personajes que son parte de su "filosofía experimental" para que tengan un fuerte impacto en el lector.

Una vez colocadas las bases de lo que trata de explicitar Oscar Daniel Choque (2018) sobre el trabajo anteriormente citado, cabe recalcar una importante relación con el aforismo 58 de La gaya ciencia (1882). En este fragmento Nietzsche nos da a conocer una mirada creadora del hombre, él mismo es el que da significado a las cosas mediante palabras o nombres; ésta es la naturaleza propia del humano, eso lo hace humano. Lo que interesa de éste aforismo es su parte final "basta con crear nuevos 
nombres y valoraciones y probabilidades, para crear a la larga nuevas <<cosas>>" (Nietzsche, 1882, pp. 67-68). Por esto mismo el filósofo alemán odiaría tanto esa carga occidental de la filosofía tradicional, todo aquel conjunto de valores, normas, moral cristiana; ya que, desde un principio, el humano al seguirlas, estaría negando su propia naturaleza, todas esas cosas decadentes suprimen esa característica esencial del humano. La arbitrariedad de colocar definiciones termina siendo la esencia, que alejada de ser real, dan formas y finalidades a las cosas.

Al resaltar esta característica del humano suena interesante encarar a la filosofía de Nietzsche como la experimental del individuo, enfocada a cada interpretación de sucesos y de lo propio vital. Una filosofía para sí mismo, que no está dirigida hacia nadie más que uno mismo. Que sirve de sustento al propio individuo para encarar lo enigmático de la existencia. Por esto mismo Nietzsche se encarga de criticar a la filosofía platónica-socrática, y tradicional en general, ya que éstas persiguen una verdad absoluta que nada tiene que ver con el propio individuo, es decir, es completamente ajeno de él, presenta un carácter trascendente; por el contrario, Nietzsche pretende una creación interpretativa de los sucesos y de la propia persona. Para que cada uno dé significado y funcionalidad a la verdad.

Por esta razón, el contenido de la obra La gaya scienza (1882), es experimental ya que su composición dicta un valor interpretativo, cada aforismo está diseñado para producir un impacto en el lector, como se dijo antes: presentar un escenario. A su vez, el interés principal de Nietzsche es presentar una filosofía volcada a lo vital, instintivo y también a la experiencia del individuo. Pretender formar una suerte de autobiografía, por ello no es pura coincidencia que Nietzsche escriba una autobiografía como Ecce Homo: cómo se llega a ser lo que se es (1908), obra en donde plasma su propia vida y cómo concebía él su vida, además de dar un plano general sobre su repertorio de escritos.

Para inducirnos dentro del porqué del estilo aforístico en La gaya ciencia (1882), es preciso rescatar esta obra de suma importancia. Ecce Homo: cómo se llega a ser el que se es (1908), como autobiografía nos dará un pantallazo bastante acertado a lo que se quiere llegar con esta monografía. 
Para dar inicio, en el prólogo ${ }^{3}$ mismo, Nietzsche empieza maldiciendo toda la tradición moral sostenida, desprecia la realidad ideal, ya que ellas son las que desvalorizan lo terrenal y mundano. Todo lo instintivo del ser humano se quema con esta moral limitadora. Para finalizar el prólogo nos deja una pequeña aclaración: nos pide que nos busquemos a nosotros mismos e ignoremos su personaje (Zaratustra). Una vez legado todo lo que nos evoca su filosofía, es preciso centrarse en un mismo, abandonando toda su filosofía. Por ello dirá: "Ahora os ordeno que me perdáis a mí y que os encontréis a vosotros; y sólo cuando todos hayáis renegado de mí volveré entre vosotros." (Nietzsche, 1908, p.21)

En el apartado denominado Por qué soy yo tan sabio (Nietzsche,1908, p.25), Nietzsche le proporciona una importancia inminente a su vida y su sufrimiento, son el lente que le permite cuestionarse cosas que no lo haría en su estado sobrio. Para el autor, es lo único que hizo que reflexionara y que se pueda dar cuenta de la decadencia; todo lo debe al estado patológico de su enfermedad. Por esta causa se considera contrario al decadente, se categoriza como un hombre libre porque acepta su sufrimiento "convertí mi voluntad de salud, de mi vida en mí filosofía" (Nietzsche, 1908, p. 27). Cuando uno recién llega al estado crítico de salud, es decir, rozando la muerte más que la vida; en ese momento uno se da cuenta del valor de la misma.

Más adelante en la obra, en la sección Por qué soy yo tan inteligente (Nietzsche, 1908, p. 41). Nos da un claro indicio de creación de nuestra propia moral a partir de nosotros, de nuestros instintos y toda la experiencia individual; no debemos atarnos a la moralidad de alguien más. Nietzsche instaura un problema que no es atendido por sus contemporáneos, o que incluso se habla muy poco. ¿Cómo logra una separación de los engaños morales cristianos? ¿Cómo dejar de consumirla como fuente de nutrición? Éstas incógnitas claramente tienen un valor experimental porque proporcionan al lector enigmas que deben ser interpretados y realizados desde la propia experiencia y desde el propio modo de interpretar la vida. Siguiendo un poco más adelante, aforismo número dos:

\footnotetext{
${ }^{3}$ Nietzsche, Ecce Homo: cómo se llega a ser el que se es (1908).
} 
Con el problema de la alimentación se halla muy estrechamente ligado el problema del lugar y del clima. Nadie es dueño de vivir en todas partes; y quien ha de solucionar grandes tareas que exigen toda su fuerza tiene aquí incluso una elección muy restringida. La influencia del clima sobre el metabolismo, sobre su retardación o su aceleración, llega tan lejos que un desacierto en la elección del lugar y del clima no solo puede alejar a cualquiera de su tarea, sino llegar incluso a sustraérsela del todo; no consigue verla jamás. El vigor animal no se ha hecho nunca en él lo bastante grande para alcanzar aquella libertad desbordante que penetra haya lo más espiritual y en la que alguien conoce: esto solo yo puedo hacerlo. Una inercia intestinal, aún muy pequeña, convertida en un mal hábito basta para hacer de un genio algo mediocre, algo <<alemán〉>; el clima alemán, por sí solo, es suficiente para desalentar a intestinos robustos e incluso nacidos del heroísmo. El tempo [ritmo] del metabolismo mantiene una relación precisa con la movilidad o la torpeza de los pies del espíritu; el <<espíritu〉> mismo, en efecto, no es más que una especie de metabolismo. (Nietzsche,1908, pp. 45-46)

Claramente Nietzsche tiene un interés bastante fuerte sobre lo fisiológico del humano, éste es tomado como central para una filosofía experimental y propia. Todo esto tiene un sentido estricto, proporcionar al lector unas instrucciones para una buena "alimentación" de la fisiología para ser el libre pensador: lugar, clima y lectura. Dentro de la constitución del humano se encuentran instintos que tienen la capacidad de derrochar o expulsar energía. En cada circunstancia dejamos rastros de energía que luego, tras haber hecho una descarga considerable; nos puede llegar a afectar.

Luego en la sección número nueve (Nietzsche,1908, pp.57-59), Nietzsche se autodenomina como un humano que realmente vivió lo que él quería, lo que sus impulsos le ordenaban; un ser que pudo ser capaz de captarse a sí mismo como en realidad es, por la constitución de su fisiología, y que para él todo lo categorizado como "malo" es sumamente importante; como dimos la referencia más arriba, sobre su enfermedad (sin ella no sería capaz de reflexionar sobre lo que reflexionó). Siguiendo el rumbo de la lectura, la sección numero 10 es muy importante para establecer una filosofía experimental en Nietzsche: 
En este punto hace falta una gran reflexión. Se me preguntaran cuál es la auténtica razón de que yo haya contado todas estas cosas pequeñas y, según el juicio tradicional, indiferentes; al hacerlo me perjudico a mí mismo, tanto más si estoy destinado a representar grandes tareas. Respuesta: estas cosas pequeñas alimentación, lugar, clima, recreación, toda la casuística del egoísmo- son inconcebiblemente más importantes que todo lo que hasta ahora se ha considerado importante. Justo aquí es preciso comenzar a cambiar lo aprendido. Las cosas que la humanidad ha tomado en serio hasta el momento no son ni siquiera realidades, son mera imaginaciones o, hablando con más rigor, mentiras nacidas de los instintos malos de naturalezas enfermas, de naturalezas nocivas en el sentido más hondo -

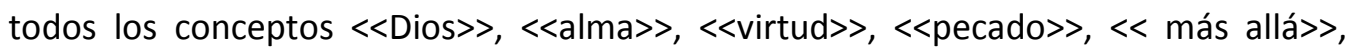
$<<$ verdad $>>,<<$ vida eterna $>>(. .$.$) (Nietzsche,1908, pp. 59-60)$

Nietzsche afirma que todas esas pequeñeces, atenientes al humano y su fisiología, son lo verdaderamente importante; por lo que, aquí se instaura la filosofía experimental del individuo. Una filosofía alejada de la concepción tradicional, una que solo atenderá al humano y lo propio de cada uno. Para poder cerrar este análisis de Ecce Homo: cómo se llega a ser lo que se es (1908), es preciso destacar el capítulo titulado "Por qué escribo yo libros tan buenos" (Nietzsche,1908, p. 63). Observamos, en la primera sección, que Nietzsche nos afirma que solo hay interpretaciones, el humano solo interpreta a partir de sus experiencias vividas. Por lo que se puede deducir que una persona además de recibir, lo condiciona a partir de sí mismo: "se carece de oídos para escuchar aquello a lo cual no se tiene acceso desde la vivencia" (Nietzsche, 1908, p. 65). De esto mismo se habla cuando se afirma una filosofía a partir del individuo, él como creador y como humano, crea su propia filosofía en base a su vida. Nietzsche mismo lo deja claro en su apartado final, "Por qué soy yo un destino" (Nietzsche, 1908, p. 135), él simplemente escribe para él mismo y desde su propia óptica. Cada una de su amplio repertorio de obras está contaminado por su propia vivencia, de hecho, así lo 
quiere. Su filosofía, su vida y su autobiografía, dentro de esta perspectiva todos estos términos son sinónimos entre sí.

Pero para poder hacer una filosofía desde la vida es necesario primero destruir o dejar en duda todas aquellas doctrinas y cargas tradicionales que tan envenenadoras del cuerpo son. Esto está más que claro cuando Nietzsche dice: "Yo soy el primer inmoralista: por ello soy el aniquilador par excellence" (Nietzsche, 1908, p. 137). Todo aquello que se deba construir desde cero debe aniquilar toda aquella base que sobra.

Aclarado por qué es importante el análisis de la autobiografía de Nietzsche, establecido lo que propone Nietzsche con su filosofía y sus obras; una suerte de filosofía desde el hombre y para el hombre (siempre desde la individual experiencia de la vida). Podemos pasar a ensayar la finalidad principal de éste trabajo. La cual, para repasar, es: ¿Por qué elige el estilo aforístico, Nietzsche, en su obra La gaya ciencia $(1882 ?$

Esta obra es de vital importancia para una filosofía experimental, aquí se pueden notar múltiples herramientas que el autor va colocando y lo hace desde una manera anti-tradicional ${ }^{4}$, el aforismo es la expresión y el resultado de todo lo criticado por Nietzsche. Podemos notar que la primera parte de la obra está dirigida a una observación rigurosa en múltiples aspectos. Se trata de un análisis detallado, por lo menos esa impresión presenta, de su cultura, sociedad, valores vigentes, entorno, etc.

Podemos notar una crítica a su sociedad contemporánea cuando en el aforismo número tres "Noble y vulgar" (Nietzsche, 1882, p. 29), nos pone sobre la mesa su odio hacia los valores nobles y que está más familiarizado con aquellos que son denominados como vulgares. "La sinrazón o la razón oblicua de la pasión es lo que el hombre vulgar desprecia en el noble, especialmente cuando este dirige su atención hacia objetos cuyo valor a él le parece completamente fantástico y arbitrario". La diferencia que hace al ser vulgar como superior al ser noble, es que, el primero posee su propio criterio de valor y además aprecia mucho más las cosas frías y oscuras; aquellas dejadas de lado por el noble, lo cual es un error garrafal del noble para Nietzsche. "El gusto del ser superior se dirige hacia la excepción, hacia cosas que

\footnotetext{
${ }^{4}$ Anti-tradicional porque se aleja de una sistematización clásica, como la de Kant u otros autores.
} 
Abril 2020.

habitualmente dejan frio y no parecen tener ninguna dulzura; el ser superior tiene un singular criterio de valor" (Nietzsche, 1882, p.30). A qué alude ese "criterio de valor", pues, a que el ser superior no está atado a ningún tipo de valor preestablecido, como hacen aquellos nobles cuando son esclavos de los valores cristianos; posee una libertad frente al bien y el mal. Todos estos valores que están siendo acribillados por la crítica nietzscheana es producto del ser superior y, a su vez, es éste el que tiene la libertad de alzar sus propios valores, a partir de su vida.

Lo que más resalta de esta primera parte es que Nietzsche se encarga de elaborar un esquema fisiológico, es decir, se atreve a describir la composición del humano cuando la asocia con el poder y la ambición del humano por la búsqueda del poder; esto lo podemos notar muy claramente en el aforismo número 13 (Nietzsche, 1882, p. 37). También resalta la fisonomía del hombre moderno, declarando que su mayor estupidez es la negación y el terror por lo extraño, por lo incierto; y esto tiene como consecuencia que el individuo no llegue a percibir eso extraño como útil y necesario para así seguir estando en la conformidad. Ésta conformidad logra instaurar en el sujeto una especie de sedentarismo por la verdad, no logra descubrir el otro lado de la verdad, no quiere destruir esa verdad que tanto anhela como conocimiento; aquella que da significado a las cosas sin cuestionarla. Tiene miedo por encontrar la verdad en la verdad, es decir, no quiere ver que esa verdad a la que tanto se acopla es simplemente un constructo del humano que le realiza con conveniencia.

Existe una humillación idiota, para nada escasa, que, cuando se está aquejado por ella, de ninguna manera sirve para ser un discípulo del conocimiento. A saber: en el instante en que un hombre de este tipo percibe algo extraño, gira inmediatamente en cierto modo sobre sus talones y se dice: «! Te has engañado! ¡Dónde dejaste tus sentidos! ¡Esto no puede ser verdad! 》 $-\mathrm{y}$ ahora bien, en lugar de mirar y escuchar una vez más atentamente a eso, se quita rápidamente y como atemorizado del camino de esa cosa extraña, e intenta sacársela de la cabeza tan rápido como sea posible. Su canon interior dice: «! No quiero ver nada que contradiga la opinión usual acerca de las cosas! ¿Es que yo estoy hecho para descubrir nuevas verdades? Ya existen demasiadas de las antiguas $\gg$. (Nietzsche, 1882, p. 25) 
También podemos destacar el análisis que realiza de la sociedad industrial, aforismo número 40 titulado: "Acerca de la falta de una forma distinguida" (Nietzsche, 1882, p. 56).

Como dijimos también se ocupa de dar un análisis de la sociedad contemporánea a él, por lo menos que de Europa y, para ser más exactos, la de Alemania. Una sociedad afectada por la necesidad de subsistir y de llenar todas las necesidades básicas a cambio de la entrega de uno mismo, a cambio de la aniquilación de todo lo natural en el humano. Un movimiento que requiere de la entrega total del individuo para alejarse del propio individuo. "Aquí opera simplemente la ley de la penuria: uno quiere vivir y tiene que venderse, pero se desprecia al que explota esta penuria y compra para sí al trabajador" (Nietzsche, 1882, p. 56). Por obligación el humano está condenado a realizar un trabajo, no por su pasión hacia él, sino más bien, por necesidad y su conservación. Avanzando un poco más en la lectura del libro podemos encontrar en la segunda parte-libro segundo una crítica a la ciencia, y aquellos que creen en una realidad existente sin antes conocerla, "A los realistas" (Nietzsche, 1882, p. 67). Una crítica que logra romper con toda verdad absoluta, aquella que tanto veneran y poco recriminan; la que desde Sócrates se viene arrastrando. Nietzsche les dará a conocer que es mucho más importante cómo se llaman las cosas, antes que lo que ellas en realidad son. El hombre tiene ese carácter creador del que se mencionó anteriormente, por lo cual tiende a necesitar de la definición a las cosas por medio de palabras.

Es importante abrir a partir de este momento la presencia de tres etapas posibles dentro de la obra La gaya ciencia (1882), una primera etapa es en la que Nietzsche despliega una serie de fragmentos que son denominados como análisis furtivo de cuestiones propias a su vida y su entorno, como vimos: sociedad, valores, ciencia, verdad, etc. La segunda etapa es el desenmascaramiento y las críticas para luego dar lugar a la tercera y última etapa, aquella reivindicación de la naturaleza humana y su vitalidad. 
Abril 2020.

ISSN 2344-9934

Un ejemplo de la segunda etapa puede ser el aforismo número 76: “El mayor peligro" (Nietzsche, 1882, p.76). Donde la racionalidad, que es el común determinante de los humanos en su época, aquellos que por obligación deben aferrarse a una verdad absoluta, son asaltados por la locura, que asecha la "ley de la coincidencia" que rige a esa sociedad. El loco custiona esa ley que tan ordenadamente mantiene a los hombres. La locura se presenta como reguladora, como aquella que mantiene los pies sobre la tierra de los hombres racionales, pone en tela de juicio la legitimidad de los investigadores de la verdad.

Se requiere entonces del mas virtuoso intelecto - - ! ah! quiero usar la palabra menos ambigua-, se requiere de la más virtuosa estupidez, se requiere de los más inconmovibles golpes de compas del espíritu lento, para que los creyentes de la gran creencia general se mantengan juntos unos a los otros y continúen bailando su baile: es una necesidad de primer rango la que aquí manda y exige. Los que somos diferentes somos la excepción y el peligro - ! eternamente requerimos defendernos! $-Y$ bien, realmente cabe decir algo a favor de la excepción, siempre y cuando nunca quiera convertirse en regla. (Nietzsche, 1882, p. 75-76)

Ésta segunda etapa se caracteriza por desenmascarar todas aquellas costumbres o conocimientos dados como verdaderos e incuestionables y también de darles con su crítica más rigurosa. Por ejemplo, en el aforismo número 84, “Acerca del origen de la poesía" (Nietzsche, 1882, p. 82), Nietzsche pretende una genealogía de lo que se denomina como poesía. Mas adelantes también, en el aforismo "Acerca del teatro" (Nietzsche, 1882, p. 85), propone una génesis de la misma. Es muy interesante ver cómo Nietzsche se encarga de hacer este tipo de trabajo, se encarga de desenmascarar aquellos orígenes que dieron lugar a determinados conceptos o cosas; que a su vez están tan instaurados y naturalizados por la sociedad de sus contemporáneos. Se encarga de hacer y de buscar una interpretación para poder explicar el origen de ciertos instintos que conforman el humano. Cómo surgieron y qué acciones humanas llevaron a la posibilidad de su potenciación. 
El curso de los pensamientos y conclusiones lógicas en nuestro cerebro actual corresponde a un proceso y lucha de instintos, cada uno de los cuales es en sí mismo bastante ilógico e injusto; corrientemente nosotros solo experimentamos el resultado de la lucha: tan rápido y tan oculto se desarrolla ahora en nosotros este antiquísimo mecanismo. (Nietzsche, 1882, p.106-107)

Nietzsche criticará a Schopenhauer en cuanto a la definición de voluntad, para Nietzsche ésta está mal planteada, ya que para él no es simplemente un querer hacer la voluntad, una simple predisposición a hacer determinada o querer determinada cosa. Existe toda una serie de mecanismos que se dan de manera exponencial, que surgen desde la propia interpretación del individuo, que se forma a partir de él:

En contraposición a él, yo planteo estas proposiciones: primero, para que surja la voluntad se necesita una representación de placer y desplacer. Segundo: el hecho de que un fuerte estimulo sea sentido como placer o desplacer es asunto del intelecto que interpreta, el que, por cierto, trabaja en nosotros la mayor parte de las veces inconscientemente; y uno y el mismo estimulo puede Ser interpretado como placentero o desplacentero. Tercero: solo para los seres inteligentes existen el placer, el desplacer y la voluntad; la gran mayoría de los organismos no sienten nada de esto. (Nietzsche, 1882, p. 116-117)

Nietzsche da a conocer el origen de la lengua alemana. Propone un análisis histórico de la misma, y cómo fue su evolución; una ascendencia hacia lo noble, un ennoblecimiento de la lengua. Éste aforismo es muy explícito y desenmascara perfectamente el origen de la lengua, "Acerca del sonido de la lengua alemana" (Nietzsche, 1882, p. 99). Un fenómeno que fue mutando a través del pasar del tiempo.

Ya en el Libro Tercero comienza con un desenmascaramiento impactante, el organismo humano, humaniza al mundo comparándolo como idénticos. Lo cual Nietzsche lo niega, para él, el mundo solo es caos y no posee ninguna característica humana. "Cuidémonos de pensar que el mundo es una criatura viviente." (Nietzsche, 1882, p. 105). El mundo no es azar, el mundo no pretende ser noble, bello o perfecto, 
Abril 2020.

ISSN 2344-9934

todas aquellas cualidades humanas, éstas son definiciones arbitrarias y originadas desde el lenguaje, que poco son propias del mundo. El universo es por necesidad y por cambio, pero no necesita del humano para seguir siendo, en cambio el humano sí.

Podemos encontrar una génesis y una crítica en un mismo aforismo, como lo es el 110 "Origen del conocimiento". El conocimiento como tal, solo existe por la fuerza, por su manera de perdurar en el tiempo, por su rigidez en el tiempo y por su manera de condicionar todo aquello que sea parte del humano. "En conclusión: la fuerza del conocimiento no reside en su grado de verdad. Sino en su antigüedad, en su hacerse cuerpo, en su carácter de condición de vida." (Nietzsche, 1882, p. 106).

Dejando en claro que Nietzsche se interesa, por lo menos en La gaya ciencia (1882), sobre el humano, su composición y sus instintos, además de un claro interés por la génesis de las cosas que por lo menos son de su interés. Cabe recalcar que esto es lo que Nietzsche quiere lograr con su filosofía, que el propio lector logre una genealogía de su propia vida, a partir de su experiencia y su cuerpo. Para ello Nietzsche deja en claro que la finalidad primordial de humano es interpretarse a uno mismo, saber cómo es y por sobre todo ser arbitrario:

A la inversa, son los débiles, que carecen de poder sobre su propio carácter, los que odian la sujeción del estilo: sienten que si se les impusiera esta amarga coacción maligna se convertirían en naturalezas ordinarias bajo ella: se convierten en esclavos tan pronto sirven, y odian servir. Tales espíritus - que pueden ser espíritus de primer orden- siempre están dispuestos a modelarse o a interpretarse a sí mismos y a su contorno como naturalezas libres: salvajes, arbitrarias, fantásticas, desordenadas, sorpresivas - !y hacen bien con ello, pues solo así se hacen un bien a sí mismos! Pues una cosa es necesaria: que el hombre alcance su satisfacción consigo mismo - ya sea a través de este o aquel poetizar y arte: !pues solo entonces se hace plenamente soportable mirar al hombre! Quien está insatisfecho consigo mismo esta constantemente dispuesto a vengarse por ello: los demás seremos sus víctimas, aunque solo 
sea porque siempre tengamos que soportar sus feas miradas. Pues la mirada de lo que es feo hace mal y pone sombrío. (Nietzsche, 1882, p. 167-168)

Nietzsche propone que seamos nosotros los interpretes de nuestras vivencias, y no ningún dogma; que lo único que hace es limitarnos y hablar por nosotros.

En la tercera etapa Nietzsche reivindica al humano, la vida y por sobre todo lo terrenal, dejar de lado todas aquellas creencias que solo prometen cosas fuera del ahora y de lo terrenal. Desintegrar todas esas suposiciones metafísicas que no hacen más que degradar a la vida del sujeto, "Pero nosotros, que somos otros, sedientos de razón, queremos mirar a nuestras vivencias con tanto rigor en los ojos, como si fuesen un experimento científico, ihora por hora, día por día! iQueremos ser nuestros propios experimentos y animales de prueba!" (Nietzsche, 1882, p. 185). Ésta es la nueva predisposición del espíritu libre, no tendrá más objetivo que ocuparse verdaderamente de sí. Una nueva libertad se funda a partir de cada uno, uno solo se preocupará de escuchar a su nuevo jefe; él mismo. Una nueva creación de valores y un entendimiento anatómico y fisiológico del individuo. Potenciar lo máximo hasta el momento la cualidad del humano, aquel creador dueño de las definiciones. El aforismo entonces, cumple el mayor papel de ésta obra filosófica, ya que el aforismo da pie para la guerra de interpretaciones, ya que el humano no puede pensar más allá de su propia perspectiva; da lugar a una reivindicación de lo singular y particular "El mundo se nos ha vuelto más bien <<infinito〉> una vez más: en la medida en que no podemos rechazar la posibilidad de que él incluye dentro de sí infinitas interpretaciones." (Nietzsche, 1882, p. 246). Ésta es la cualidad propia que presenta el aforismo, en cambio lo sistemático tradicional, no puede dar inicio a una infinidad de interpretaciones, se puede decir que está atado a una linealidad y un camino recto. Pero para poder llegar a este punto es necesario, siguiendo a Nietzsche, pasar por las dos primeras etapas de la obra. Recordamos que la primera es un análisis de las cuestiones propia de la vida y su entorno, pasando por la segunda que es un desenmascaramiento y crítica de todo aquello que no fue cuestionado. Para dar lugar a una transvaloración a partir de los fragmentos o aforismos que Nietzsche construyó. 
Abril 2020.

ISSN 2344-9934

Por esta misma razón suena bastante coherente que el propio autor no quiera que se lo santifique, que lo sigamos, porque estaríamos rompiendo con una f filosofía experimental propia del individuo.

\section{Conclusión}

Se puede concluir que, siguiendo a Andreas Urs Sommer, la filosofía experimental de Nietzsche procura, mediante herramientas lingüísticas, lograr establecer en el lector un determinado escenario que luego debe ser re-pensado y asimilado por aquel que lo adquiere (el que lee el fragmento). La constitución general de la obra La gaya ciencia (1882) posee tres etapas o tópicos, que sirven para determinar la funcionalidad del aforismo en dicha obra; exhortar al lector para crear una filosofía, a partir de su propia fisiología y su perspectiva. Junto con el análisis breve de Ecce homo: cómo se llaga a ser lo que se es (1908) y la composición de La gaya ciencia (1882) se concluye que la filosofía experimental de Nietzsche está volcada a la interpretación individual del humano y rompe con toda concepción tradicional de la misma. El foco principal de esta nueva concepción sería generar una propia construcción de valores a partir de lo instintivo y la experiencia de la persona. 


\section{Bibliografía}

- Cioran, E,M. (1995). Ese maldito yo. Tusquets Editores S.A. España.

- Deleuze, G (1965). Nietzsche. Trad. Herrera, I y Del Río, A, Arena Libros, España

- Morrilla, J. (2019). Consideraciones acerca de la filosofía experimental de

Friedrich Nietzsche. A propósito de la obra Nietzsche und die Folgen de Andreas Urs Sommer. Daimon, Revista internacional de filosofía. España

- Nehamas, A. (2002). La vida como literatura. Trad.García, R.J, Turner publicaciones S.L, México

- Nietzsche, F. (1908). Ecce homo: cómo se llega a ser lo que se es. Trad. Andrés Sánchez Pascual, Alianza Editorial. España, Madrid

- Nietzsche, F. (1999). La ciencia jovial.Trad. José Jara, Monte Ávila. Venezuela

- Osman Choque, D. (2018). El filósofo y su filosofía: La "filosofía experimental" de Nietzsche. Fragmentos de filosofía, España

- Pascal, B. (2012). Pensamientos. Trad. Herederos de Carlos, De Dampierre.

Editorial Gredos, S.A. España 